Published in final edited form as:

Otol Neurotol. 2012 February ; 33(2): . doi:10.1097/MAO.0b013e31821a80f8.

\title{
Temporal Bone Histopathology Case of the Month:
}

\section{Langerhans' Cell Histiocytosis of the Temporal Bone}

\author{
Muzeyyen Yildirim-Baylan ${ }^{*},+$ Sebahattin Cureoglu ${ }^{*}$, and Michael M. Paparella ${ }^{\ddagger}$ \\ *Department of Otolaryngology, University of Minnesota, Minneapolis, Minnesota, U.S.A \\ †Department of Otolaryngology, University of Dicle, Diyarbakir, Turkey \\ ‡Paparella Ear Head and Neck Institute, Minneapolis, Minnesota, U.S.A
}

\begin{abstract}
Langerhans' cell histiocytosis ( $\mathrm{LCH}$ ) is characterized by an abnormal polyclonal proliferation and accumulation of Langerhans' cells. Langerhans' cells are macrophages that are primarily located in the dermis. $\mathrm{LCH}$ also is known as histiocytosis $\mathrm{X}$ and includes 3 clinical syndromes: 1) eosinophilic granuloma, 2) Hand-Schuller-Christian disease, and 3) Letterer-Siwe disease (1). LCH is usually seen in the head and neck and mainly in the cranial base in $60 \%$ of cases (2). It is a rare disease with a male predominance most commonly seen in children, especially between ages 1 and 4 years, but can be found at any age. Children younger than 2 years have a poor prognosis (1).

In this study, a temporal bone with Langerhans' cell histiocytosis of subtype Letterer-Siwe was presented.
\end{abstract}

\section{CASE REPORT}

This is the case of a 22-month-old child who was diagnosed with LCH of subtype LettererSiwe by biopsy from skin and liver. He was treated with chemotherapy (including Cytoxan, methotrexate, vinblastine, and prednisone) and radiotherapy. An otoscopic examination showed bilateral serous otitis media. He died of respiratory failure 18 months after the diagnosis of LCH. Autopsy revealed LCH in the skin, cranium, lungs, liver, spleen, and possibly the posterior pituitary gland. The autopsy findings also indicated pneumonia caused by Pneumocystis carinii.

\section{Histopathology}

Right and Left Temporal Bones-The external auditory canal, tympanic membrane, cochlea, and petrous apex were damaged upon the removal of the both temporal bones and could not be evaluated. In both right and left temporal bones, all the middle ear and mastoid cells were filled with the pathologic tissue, which is characteristic of Langerhans' cell histiocytosis (Fig. 1). In the right temporal bone, the incudomalleolar junction was infiltrated by LCH tissue (Fig. 1). The microscopic examination of this tissue showed dense infiltrations of Langerhans' cells with a variable number of lymphocytes, eosinophils, giant cells, and histiocytes (Fig. 2). The mastoid segment of the facial nerve was dehiscent in both right and left temporal bones. No invasion was seen in the vestibule, semicircular canals, or internal auditory canal. 


\section{DISCUSSION}

The most common otologic presentations of LCH patients are otorrhea, otalgia, otorrhagia, postauricular swelling, pain on pressure, facial paralysis, conductive hearing loss, and sensorineural hearing loss (3). Plain radiographs are helpful for diagnosis of LCH bone lesions. They might demonstrate a "punched out" radiolucency with a sharply defined margin (4). The computerized tomographic scan is the gold standard for imaging the temporal bone lesions (3).

In patients with temporal bone $\mathrm{LCH}$, a definitive diagnosis is based on pathologic and immunohistochemical findings. Microscopically, the lesions are characterized by Langerhans' cells with grooved, folded, or coffee bean-shaped nuclei, with fine nuclear chromatin, and unremarkable nucleoli. Langerhans' cell histiocytosis is usually associated with a rich inflammatory cell infiltrate including lymphocytes, plasma cells, multinucleated giant cells, and usually most notably, a large number of eosinophils. S100 protein and CD1a immunostaining helps to confirm the diagnosis of LCH (4).

There are several treatment modalities for temporal bone LCH including surgery, radiotherapy, chemotherapy, and steroid injection. They can be used alone or in combination, depending on the extent and severity of disease (1).

In patients with $\mathrm{LCH}$ presenting to a clinic with otologic symptoms, physicians should keep in mind the possibility of invasion of Langerhans' cells in to the ear as a cause for the otologic symptoms.

\section{Acknowledgments}

Funding/Support: This study was supported by the National Institute on Deafness and Other Communication Disorders (3U24 DC008559-035109), 5M Lions International, the International Hearing Foundation, and the Starkey Foundation.

The authors thank Evin Gulbahce, M.D., from the Department of Laboratory Medicine and Pathology, University of Minnesota, for help in diagnosing the Langerhans' cell histiocytosis of the temporal bone, and Carolyn Sutherland and Monika Schachern for technical assistance.

\section{References}

1. Martini A, Aimoni C, Trevisani M, Marangoni P. Langerhans' cell histiocytosis: report of a case with temporal localization. Int J Pediatr Otolaryngol. 2000; 55:51-6.

2. Krishna H, Behari S, Pal L. Solitary Langerhans-cell histiocytosis of the clivus and sphenoid sinus with parasellar and petrous extension: a case report and a review of the literature. Surg Neurol. 2004; 62:447-54. [PubMed: 15518856]

3. Saliba I, Sidani K, El Fata F, Arcand P, Quintal MC, Abela A. Langerhans' cell histiocytosis of the temporal bone in children. Int J Pediatr Otolaryngol. 2008; 72:775-86.

4. Nelson BL. Langerhans' cell histiocytosis of the temporal bone. Head Neck Pathol. 2008; 2:97-8. [PubMed: 20614330] 


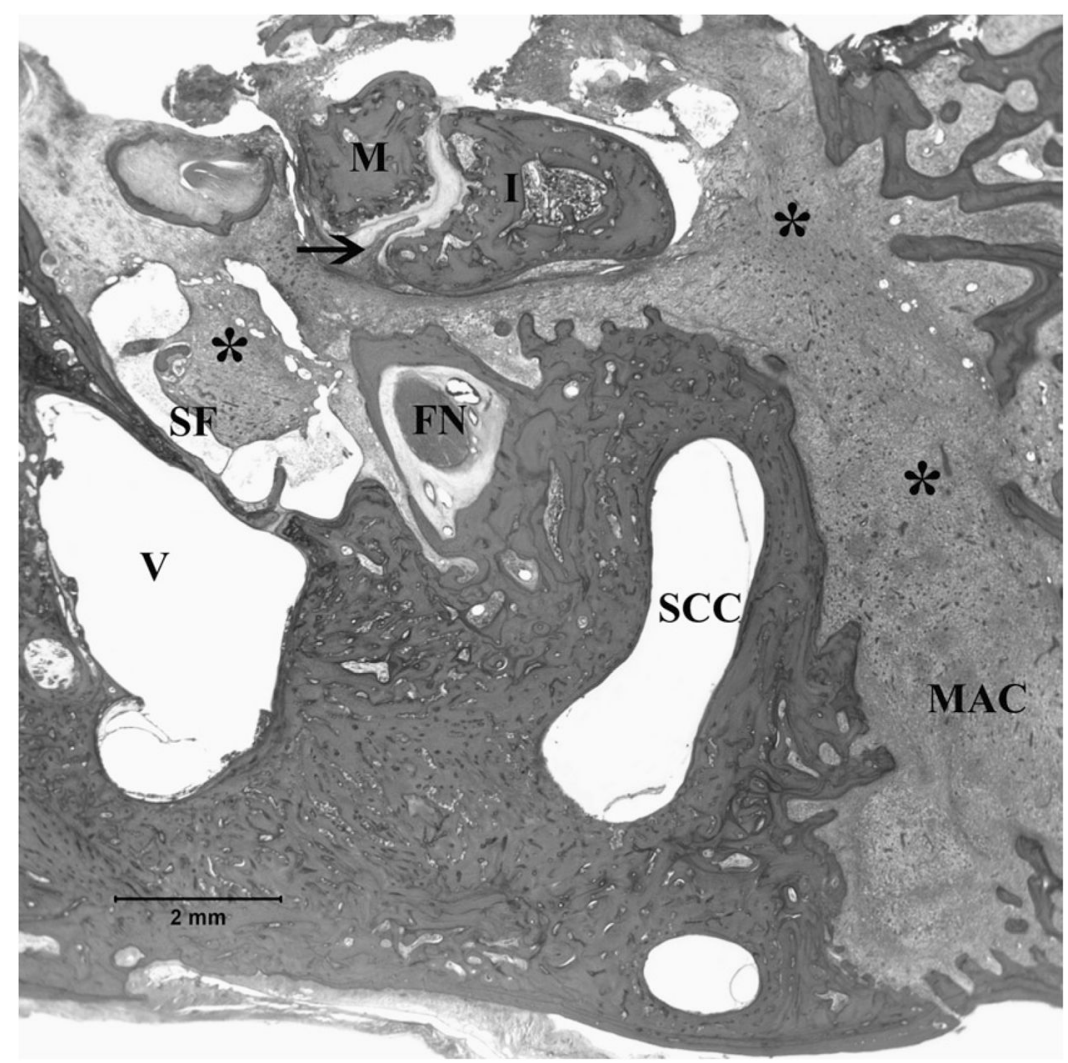

FIG. 1.

In the right temporal bone, the middle ear and mastoid cells were filled with pathologic tissue (asterisk), which is characteristic of Langerhans' cell histiocytosis. Incudomalleolar joint invasion by Langerhans' cell histiocytosis (arrow) (hematoxylin and eosin; original magnification, $\times 1$ ). FN indicates facial nerve; I, incus; M, malleus; MAC, mastoid air cells; SCC, semicircular canal; SF, stapes footplate; V, vestibule. 


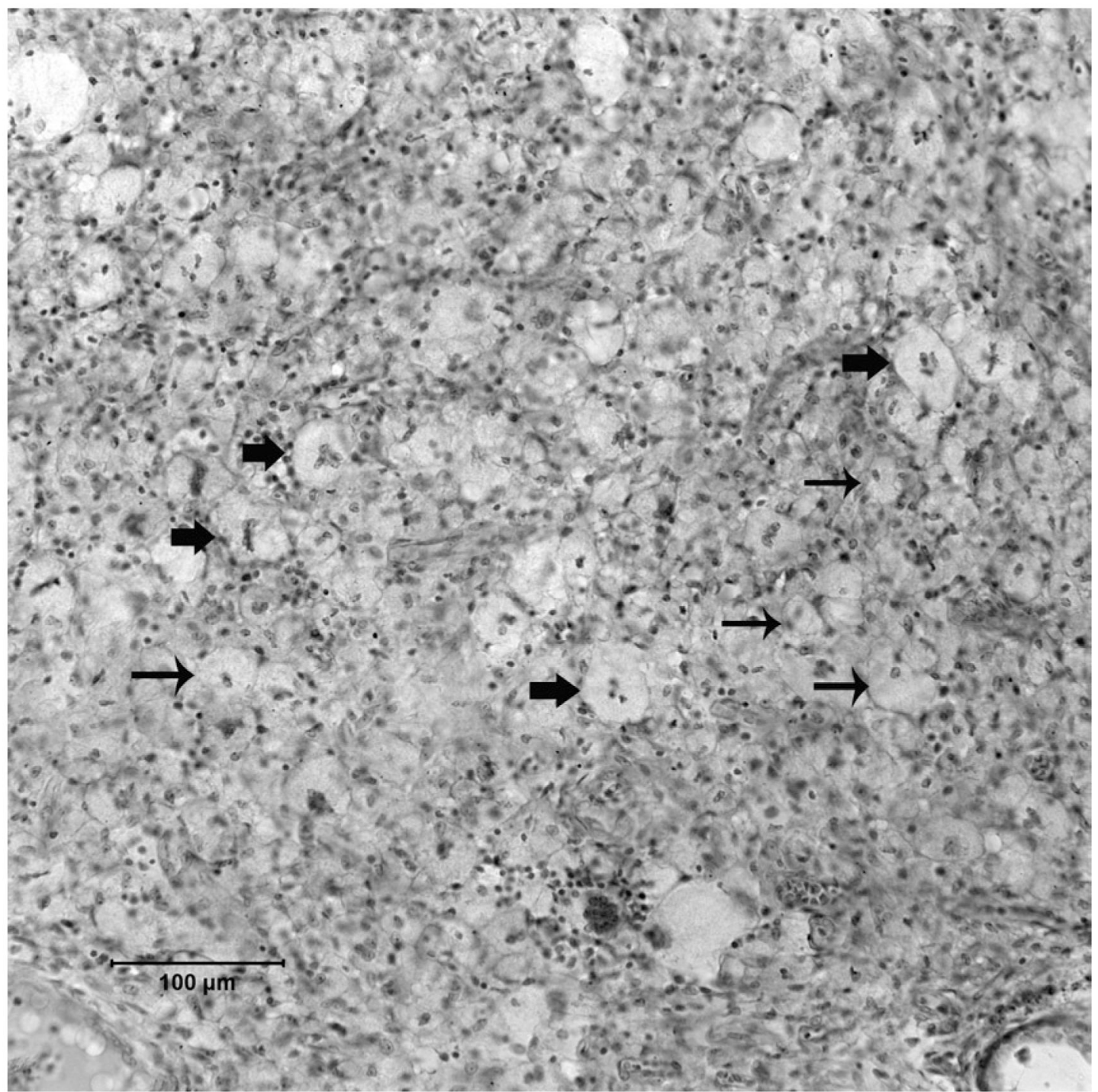

FIG. 2.

Most of the middle ear space and mastoid cells were replaced with mononuclear cells including Langerhans' cells and foamy macrophages (histiocytes) with scattered giant cells (thin arrow, histiocytes; thick arrow, multinucleotide giant cells) (hematoxylin and eosin; original magnification, $\times 20$ ). 